\title{
Estimation of Candida albicans ABC Transporter Behavior in Real-Time via Fluorescence
}

\author{
Joanna Szczepaniak, Marcin Łukaszewicz and Anna Krasowska* \\ Faculty of Biotechnology, University of Wroclaw, Wroclaw, Poland
}

We present a fluorometric method for determining $A B C$ transporter activity in the pathogenic fungus $C$. albicans during different growth phases and in response to glucose. The carbocyanine dye diS- $\mathrm{C}_{3}(3)$ was previously used to monitor plasma membrane potentials and test the influence of surface-active compounds in membrane polarization. We used diS- $\mathrm{C}_{3}(3)$ to show changes in fluorescence kinetics that reflect changes in the activity of $A B C$ transporters in $C$. albicans growth. Cdr1-GFP fluorescence, revealed that Cdr1p relocates to the inside of the cell after the early-log growth phase. Addition of glucose to the cell suspension resulted in Cdr1p transporter expression in the CDR2-knockout strain. We confirmed the diS- $\mathrm{C}_{3}(3)$ results by standard RT-PCR and Western blotting.

New York Institute of Technology College of Osteopathic Medicine,

Keywords: diS- $\mathrm{C}_{3}(3)$ fluorescence, protein localization imaging, kinetics of efflux pump activity, Candida albicans, CDR

Reviewed by:

Joseph M. Bliss,

Women \& Infants Hospital of Rhode Island, USA

lan A Cleary,

University of Tennessee at Martin,

*Correspondence:

Anna Krasowska

anna.krasowska@uwr.edu.pl

Specialty section:

This article was submitted to

Fungi and Their Interactions,

a section of the journal

Frontiers in Microbiology

Received: 07 October 2015

Accepted: 20 November 2015

Published: 09 December 2015

Citation:

Szczepaniak J, Łukaszewicz M and Krasowska A (2015) Estimation of Candida albicans ABC Transporter Behavior in Real-Time via

Fluorescence.

Front. Microbiol. 6:1382.

doi: 10.3389/fmicb.2015.01382

\section{INTRODUCTION}

Candida albicans normally occurs as a relatively harmless organism in the human microbiome (Koh, 2013); however, C. albicans infection can be triggered by various perturbations in homeostasis, such as compromised immune defense or breaks in the epithelium-blood barriers due to injury or surgery. Interestingly, the risk of infection is also increased in diabetic patients (Perlroth et al., 2007), possibly due to the dramatic effects of glucose on C. albicans' metabolism (Brown et al., 2014) that increase virulence and drug resistance (Rodaki et al., 2009; Ene et al., 2012; Mandal et al., 2014). Moreover, Mandal et al. (2014) found that glucose selectively interacts with commonly used antifungal agents by forming complexes via hydrogen bonding, which, in turn, lowers their efficacy. The growing number of C. albicans strains resistant to pharmaceuticals is decreasing the already low number of drugs available to treat candidiasis. Due to C. albicans' multiple mechanisms to adapt to and resist drugs, new experimental approaches must be developed to define the in vivo and/or real-time behaviors of individual cells (Brown et al., 2014). Many of C. albicans' adaptations and resistance mechanisms are related to the supramolecular structure formed by the cell wall and plasma membrane. Active transport through the plasma membrane is driven by transporters powered by high energy compounds, such as ATP, and/or membrane potential (Cannon et al., 2009). Thus, it is very important to develop methods to directly monitor drug transporters and plasma membrane-related activity in C. albicans.

Candida albicans' drug transporters were previously investigated via heterologous expression in Saccharomyces cerevisiae, but growing evidence indicates that C. albicans' metabolism is different from that of $S$. cerevisiae, especially in terms of major transcriptional modifications and resistance to osmotic stress and antifungal drugs (Garreau et al., 2000; Gasch et al., 2000; Ene et al., 2012; 
TABLE 1 | Candida albicans strains used in this study.

\begin{tabular}{|c|c|c|}
\hline Strain & Genotype & Reference \\
\hline CAF 2-1 & ura3 $\Delta:: i m m 434 / U R A 3$ & Fonzi and Irwin, 1993 \\
\hline DSY 448 & cdr1 1 ::hisG-URA3-hisG/cdr1 1 ::hisG & Sanglard and Ischer, 1996 \\
\hline DSY 653 & cdr2 $\Delta::$ hisG-URA3-hisG/cdr2 $\Delta::$ hisG & Sanglard et al., 1997 \\
\hline DSY 654 & $\begin{array}{l}\operatorname{cdr1} 1 \text { ::hisG/cdr1 } \Delta:: \text { hisG } \\
\text { cdr2 } \Delta:: \text { hisG-URA3-hisG/cdr2 } \Delta: \text { hisG }\end{array}$ & Sanglard et al., 1997 \\
\hline DSY 4-2 & ura3 $\Delta:: i m m 434 /$ ura3 $\Delta:: i m m 434$ & Fonzi and Irwin, 1993 \\
\hline ASCa1 & ura3 $\Delta:: i m m 434 / U R A 3$ CDR1-GFP & This study \\
\hline
\end{tabular}

Szczepaniak et al., 2015). Glucose, for example, enhances oxidative stress resistance in $C$. albicans but decreases stress resistance in S. cerevisiae (Garreau et al., 2000; Gasch et al., 2000). Therefore, it is very important to account for many factors when looking for new, efficient treatment strategies of candidiasis.

We developed a fluorescence method that allows in vivo realtime monitoring of the activity of C. albicans' drug efflux pumps, Cdr1p, and Cdr2p, using a 3,3'-dipropylthiadicarbocyanine (diS$\mathrm{C}_{3}(3)$ ) probe (Szczepaniak et al., 2015). The method is based on the property of $\operatorname{diS}-\mathrm{C}_{3}(3)$ to increase $\lambda_{\max }$ after binding to cell constituents (mostly proteins); since the maximum fluorescence wavelength of the bound probe is about $10 \mathrm{~nm}$ higher than that of the free probe in solution, it allows us to observe its accumulation in cells and thereby monitor the actions of the probe-expelling pumps. This method also allows us to examine membrane potential differences in $S$. cerevisiae based on the changes of the fluorescence spectra of diS$\mathrm{C}_{3}$ (3) from equilibrium (Plášek et al., 2012). In this work, we used $\operatorname{diS}-\mathrm{C}_{3}(3)$ to assess the scope of $C$. albicans $\mathrm{ABC}$ transporter activity in response to membrane potential changes and glucose.

\section{MATERIALS AND METHODS}

\section{Strains and Growth Media}

The C. albicans strains used in this study (Table 1) were generous gifts from D. Sanglard (Lausanne, Switzerland). All strains were grown at $28^{\circ} \mathrm{C}$ on YPD medium with $2 \%$ glucose, $1 \%$ Bacto peptone (Difco), and $1 \%$ yeast extract (Difco) with shaking at $120 \mathrm{rpm}$. Solid medium was supplemented with $2 \%$ agar.

\section{Strain Construction}

Strain ASCa1 was constructed by integration of the CDR1-GFPURA3 cassette into the chromosomal locus of CDR1 in the CAF 4-2 strain, as described by Gerami-Nejad et al. (2001). CDR1specific sequences were added to universal primers to generate primers AS001 and AS003. We used primers AS003 and AS004 to verify integration into the chromosomal locus of CDR1 (Table 2).

\section{Sample Preparation}

Cells were prepared according to the method of Gásková et al. (1998), with modifications. One hundred and fifty microliter of overnight, stationary culture were added to $20 \mathrm{ml}$ of fresh YPD medium and incubated at $28^{\circ} \mathrm{C}$ with shaking at $120 \mathrm{rpm}$ for
TABLE 2 | Primers used in this study.

\begin{tabular}{|c|c|c|}
\hline Primer name & Sequence & Reference \\
\hline AS001 & $\begin{array}{l}\text { CATTCTTACGGTGATCTITATTGGT } \\
\text { TAGCCAGAGAGAATAGAGTTCCAAAG } \\
\text { GGTAAAAAAAATAAGAAAGGTGGT } \\
\text { GGTTCTAAAGGTGAAGAATTATT }\end{array}$ & Larsen et al., 2006 \\
\hline AS002 & $\begin{array}{l}\text { ACAACAACAATAGTCTAAAAACGTC } \\
\text { TATTATATITAGACGTTGAGATACC } \\
\text { ACCATGTCAAAAAACAAATCTAGAAG } \\
\text { GACCACCTITGATTG }\end{array}$ & \\
\hline ASO03 & ACATTAAATITGCTGGTGGG & This study \\
\hline AS004 & CCTTCTGGCATGGCAGACTTG & \\
\hline ACT1-F & ПTTAAGAATTGATाTGGCT & Murzyn et al., 2010 \\
\hline ACT1-R & GAAGATTGAGAAGAAGTाT & \\
\hline CDR1-F & TGCCAAACAATCCAACAA & Ricardo et al., 2009 \\
\hline CDR1-R & CGACGGATCACCTICATACGA & \\
\hline
\end{tabular}

10,14 , or $24 \mathrm{~h}$. The cells were then harvested by centrifuging at $110 \times g$ for $3 \mathrm{~min}$, washing twice with deionised water, and resuspending in citrate-phosphate (CP) buffer $(\mathrm{pH} \mathrm{6.0)}$ at $\mathrm{OD}_{600}=0.1$.

\section{DiS- $\mathrm{C}_{3}(3)$ Uptake into Cells}

Samples $\left(3 \mathrm{ml}, \mathrm{OD}_{600}=0.1\right)$ were labeled with $\operatorname{diS}-\mathrm{C}_{3}(3)$ at a final concentration of $5 \times 10^{-8} \mathrm{M}$ at room temperature. Fluorescence spectra were measured every $4 \mathrm{~min}$ for $120 \mathrm{~min}$, with gentle stirring before each measurement, on a Fluorescence Spectrophotometer (HITACHI F-4500) equipped with a xenon lamp. The excitation wavelength was $531 \mathrm{~nm}$ and the fluorescence range was 560-590 $\mathrm{nm}$. Scattered light was eliminated by an amber glass filter with a cut-off wavelength of $540 \mathrm{~nm}$. If indicated, glucose was added at a final concentration of $2 \%$.

\section{Microscopy Studies}

Strains were grown for $24 \mathrm{~h}$ in YPD medium at $28^{\circ} \mathrm{C}$ with shaking at $120 \mathrm{rpm}$. At indicated times, aliquots of cell culture were pelleted by centrifuging, washed in deionised water, and $4 \mu \mathrm{l}$ of samples were visualized with a ZEISS AXIO IMAGER.A2.

\section{Real-time PCR}

The assay was prepared from samples $\left(5 \mathrm{ml}, \mathrm{OD}_{600}=0.4\right)$ after staining with $2 \times 10^{-7} \mathrm{M}$ diS- $\mathrm{C}_{3}$ (3) probe for 40,72 , or $96 \mathrm{~min}$, with $2 \%$ glucose added after $60 \mathrm{~min}$ if indicated. Aliquots of cell suspensions were pelleted by centrifuging at $2260 \times g$ for $5 \mathrm{~min}$. Cells were resuspended in lysis buffer (1 M sorbitol, $0.1 \mathrm{M}$ EDTA, $1 \% \beta$-mercaptoethanol, $2.5 \mathrm{mg} / \mathrm{ml}$ zymolyase), incubated at $37^{\circ} \mathrm{C}$ for $30 \mathrm{~min}$, and centrifuged at $2834 \times g$. Total RNA was extracted using a Total RNA Mini kit (A\&A Biotechnology) according to the manufacturer's instructions. The purity and concentration of RNA samples were determined from A260/A280 readings and RNA integrity was checked by electrophoresis. Samples were treated with DNAse I (Fermentas) to remove genomic DNA contamination. The cDNA was synthesized using $0.5 \mu \mathrm{g}$ RNA with a High-Capacity cDNA Reverse Transcription Kit (Applied Biosystems). Real-time PCR reactions with performed with a DyNAmo HS SYBR Green 
qPCR Kit (Thermo Scientific) and a 7500 Real-Time PCR System (Applied Biosystems). Gene-specific primers for actin (ACT1-F and ACT1-R) and CDR1 (CDR1-F and CDR1-R) were used. The thermal cycling conditions consisted of the initial step at $50^{\circ} \mathrm{C}$ for $2 \mathrm{~min}$, then $95^{\circ} \mathrm{C}$ for $10 \mathrm{~min}$, followed by 35 cycles at $95^{\circ} \mathrm{C}$ for $20 \mathrm{~s}, 45^{\circ} \mathrm{C}$ for $20 \mathrm{~s}$, and $72^{\circ} \mathrm{C}$ for $30 \mathrm{~s}$. The gene expression level of the wild-type strain at $40 \mathrm{~min}$ of incubation, relative to that of the other time points, was calculated using the formula $2^{-\Delta \Delta \mathrm{CT}}$.

\section{Western Blotting}

The assay was performed according to the method of Hiller et al. (2006), with modifications. Crude protein extract was prepared from samples $\left(5 \mathrm{ml}, \mathrm{OD}_{600}=0.4\right)$ after staining with $2 \times 10^{-7} \mathrm{M}$ diS $-\mathrm{C}_{3}(3)$ probe for $10,40,72$, or $96 \mathrm{~min}$, with $2 \%$ glucose added after $60 \mathrm{~min}$ if indicated. Aliquots of cell suspensions were pelleted by centrifuging at $2260 \times g$ for $5 \mathrm{~min}$ and resuspended in $1 \mathrm{ml}$ of deionised water. Cells were lysed by the addition of $150 \mu \mathrm{l}$ of $1.85 \mathrm{M} \mathrm{NaOH}$ $7.5 \% \beta$-mercaptoethanol and incubated on ice for $10 \mathrm{~min}$. Proteins were precipitated by the addition of $150 \mu \mathrm{l}$ of $50 \%$ trichloroacetic acid and incubated on ice for $10 \mathrm{~min}$. Samples were then centrifuged at $10,000 \times g$ for $5 \mathrm{~min}$ at $4^{\circ} \mathrm{C}$, washed in $1 \mathrm{ml}$ of $1 \mathrm{M}$ Tris- $\mathrm{HCl}(\mathrm{pH} 8.0)$, and resuspended in $20 \mu \mathrm{l}$ sample buffer (40 mM Tris- $\mathrm{HCl}, 8 \mathrm{M}$ urea, 5\% SDS, $0.1 \mathrm{mM}$ EDTA, $1 \% \beta$-mercaptoethanol, $0.1 \mathrm{mg} / \mathrm{ml}$ bromophenol blue), followed by incubation at $37^{\circ} \mathrm{C}$ for $30 \mathrm{~min}$. Five microliter of protein extract were loaded in a $10 \%$ sodium dodecyl sulfatepolyacrylamide gel and electrophoresed in a Mini-PROTEAN II electrophoresis cell (Bio-Rad). After the electrophoresis, the samples were transferred onto a nitrocellulose membrane using a Mini-PROTEAN Tetra System electrophoresis cell (Bio-Rad). The membranes were stained with Ponceau $S$ to check for equal loading of the gels. Immunodetection of Cdr1p was performed using a polyclonal rabbit anti-Cdr1p antiserum (a generous gift from D. Sanglard, Lausanne, Switzerland) and horseradish peroxidase-conjugated anti-rabbit antiserum as a secondary antibody. Signals were detected using an ECL kit from PerkinElmer according to the manufacturer's instructions.

\section{RESULTS AND DISCUSSION}

\section{Membrane Potential, as Measured by diS- $\mathrm{C}_{3}(3)$ Fluorescence, is a Factor in ABC Transporter Activity During Phases of C. albicans Growth}

As indicated by Plášek et al. (2012) and Plášek and Gášková (2013), diS- $\mathrm{C}_{3}(3)$ is a suitable probe to monitor real-time changes in plasma membrane potential; here, we are the first to describe this use in $C$. albicans. To monitor the changes we measured the fluorescence $\lambda_{\max }$ in the strain without ABC transporters to remove their effect on probe efflux. Probe accumulation took only $30 \mathrm{~min}$ in the early log-phase but took 60 and $50 \mathrm{~min}$, respectively, to accumulate after 14 and $24 \mathrm{~h}$ in culture (Figure 1). As cultures age, the cells and the structure and function of their membranes change. The kinetics of diS- $\mathrm{C}_{3}(3)$ fluorescence (Figure 1) reflect changes in the membrane potential of cells in different phases of growth. An age-induced reduction in membrane potential correlates with decreased polarization (Kumar et al., 2015). Cell membrane depolarisation can cause lateral redistribution of membrane proteins (Grossmann et al., 2007). Kumar et al. (2015) found that membrane fluidity contributes to drug diffusion and resistance. Higher membrane fluidity can lead to incorrect localization of the Cdrlp pump and thus lack of Cdr1p activity. The C. albicans strain with CDR1 overexpression and drug resistance had a more rigid membrane than the drug-sensitive strain; this rigidity increased until the late-log phase of growth. On the other hand, the wild-type C. albicans SC5314 increased the fluidity of its membrane during growth. In the $C$. albicans mutants with deletion of a key component required during the biogenesis of mitochondria, decreases in the cellular ergosterol level and mis-sorting of Cdrlp into vacuoles were observed (Thomas et al., 2013). Similar effects were observed in the S. cerevisiae strain expressing $C$. albicans CDR1 with deletions in the genes involved in ergosterol synthesis (Pasrija et al., 2008). Mukhopadhyay et al. (2004) found that Cdr1p dislocated from the cell membrane after incubating Saccharomyces cells
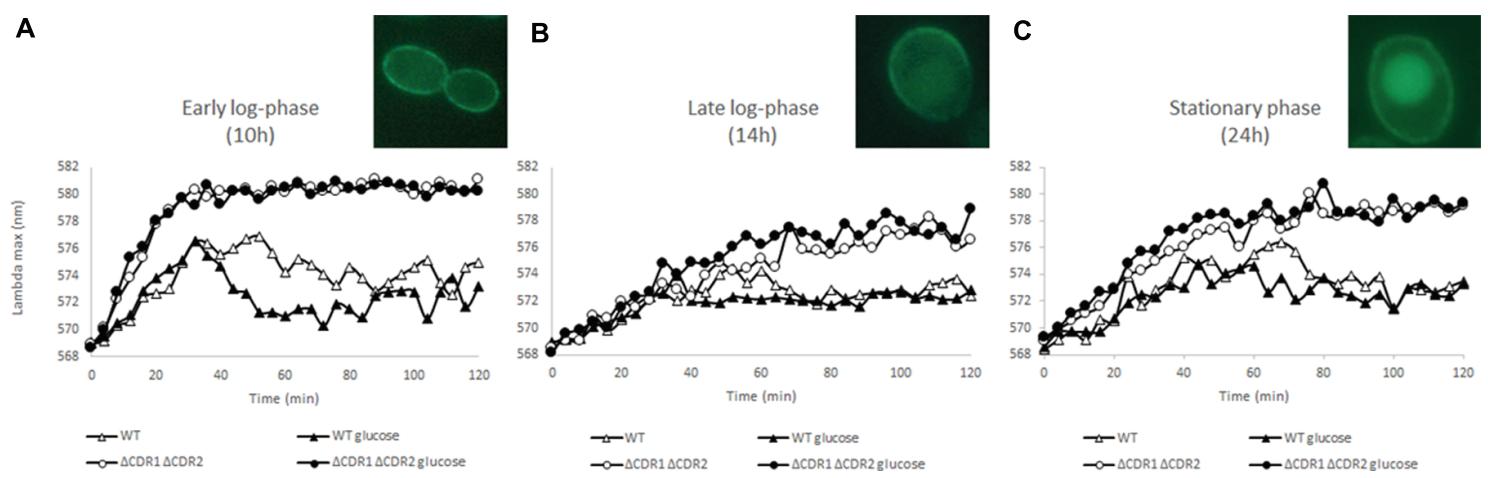

FIGURE 1 | DiS-C3(3) fluorescence staining of wild-type and CDR1 $\Delta$ CDR2 $\Delta$ strains during early log-phase (A), late log-phase (B), and stationary phase (C). $2 \%$ glucose was added at the start of the experiment $(n=3)$. Pictures: Cdr1-GFP localization during (A-C). 


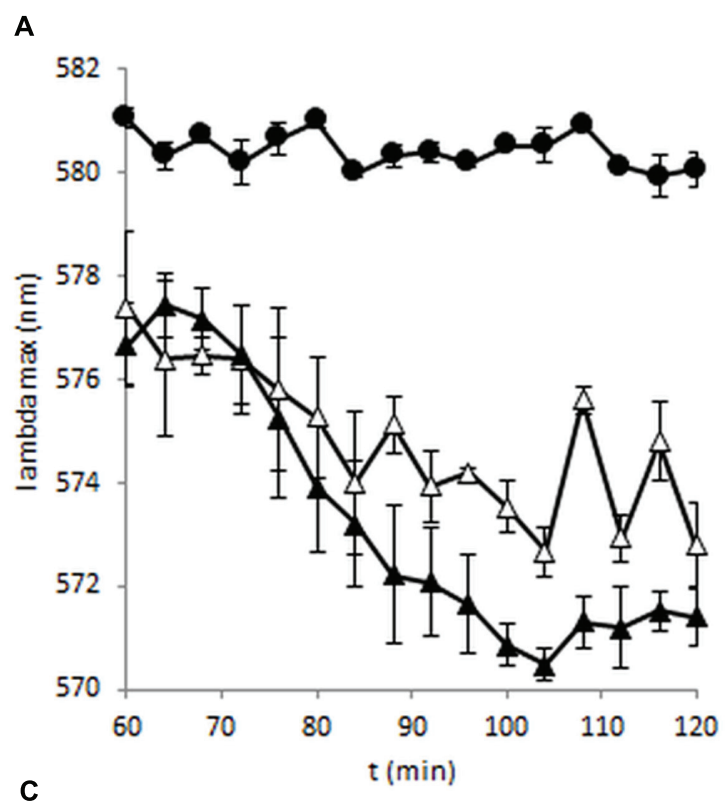

B
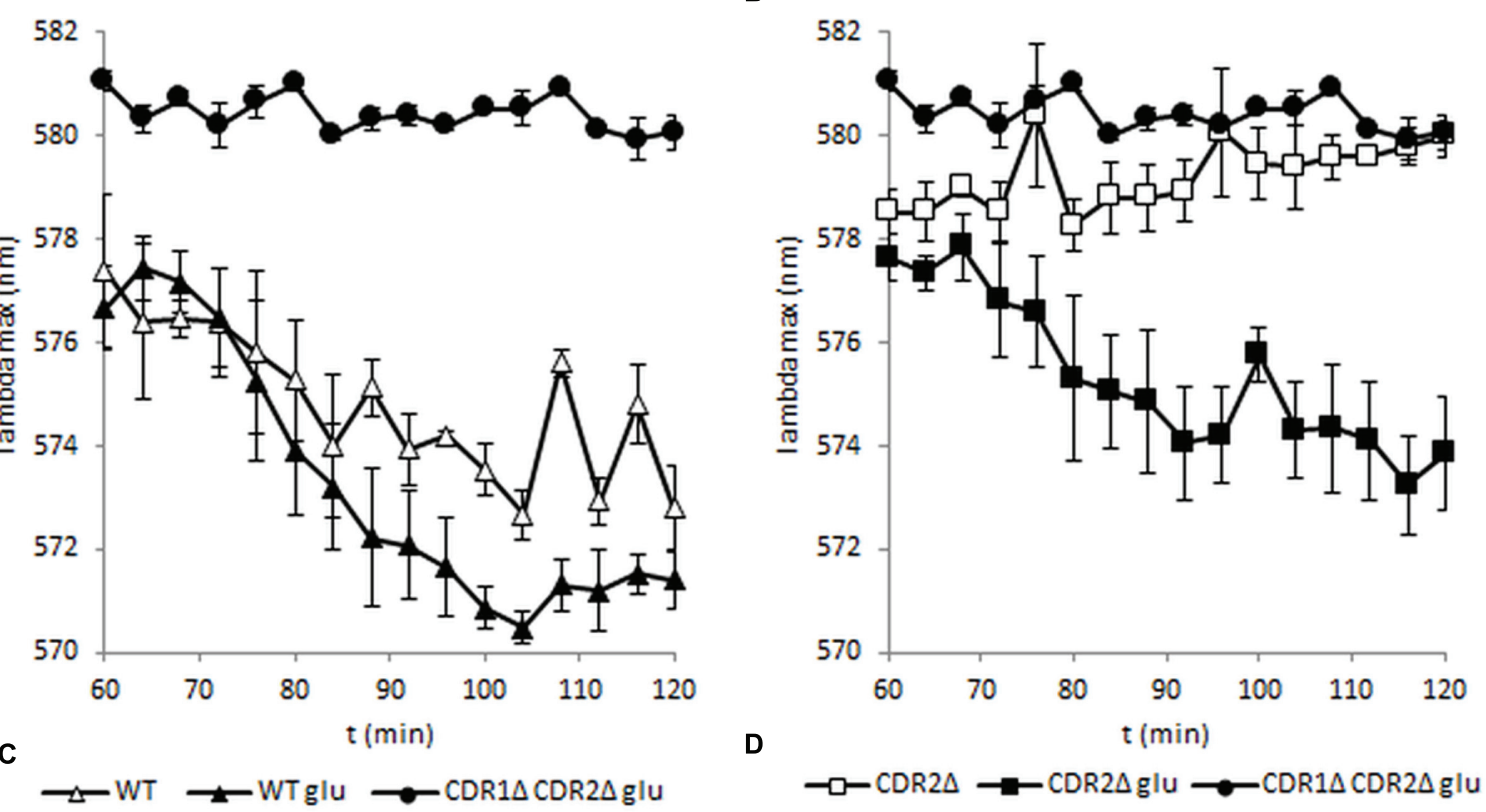

$\rightarrow-\operatorname{CDR} 2 \Delta \rightarrow-\operatorname{CDR} 2 \Delta$ glu $\longrightarrow \operatorname{CDR} 1 \Delta \operatorname{CDR} 2 \Delta$ glu

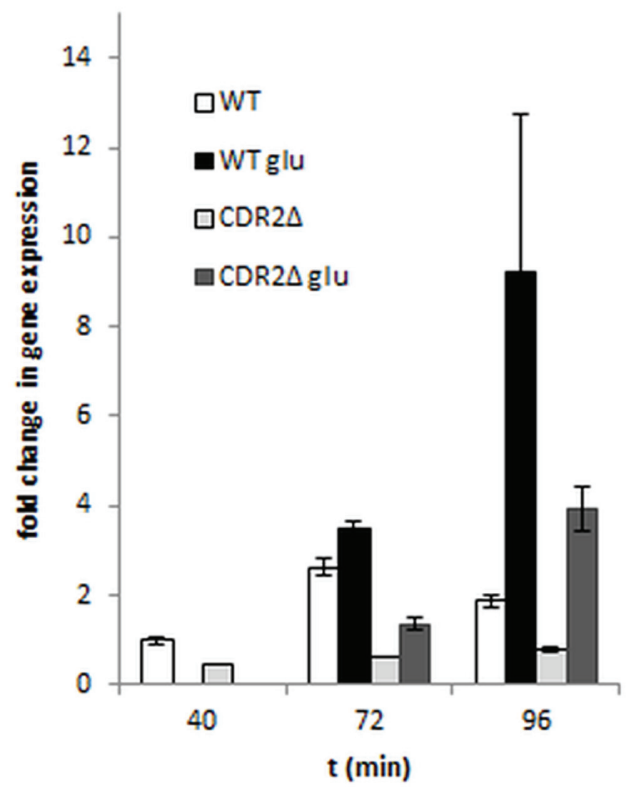

Time after beginning of the experiment ( $\mathrm{min}$ )

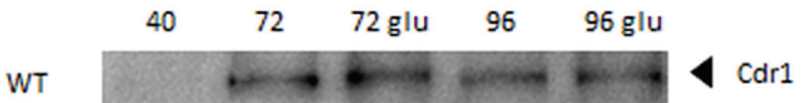

CDR2A

Cdr1

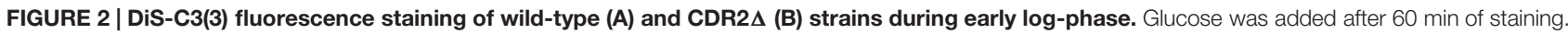
(C) Expression of CDR1 during the experiment. Samples were taken at 40, 72, or $96 \mathrm{~min}$ from the beginning of the experiment. (D) Cdr1 protein levels during the experiment. Samples were taken at 40, 72, or 96 min from the beginning of the experiment $(n=3)$.

with filipin, which interacts with the 3-hydroxyl group of membrane sterols. In this study, we observe that the Cdrlp pump fused with GFP is located in the plasma membrane in the early logarithmic phase (Figure 1A). Starting from the $14 \mathrm{~h}$ late log-phase, the movement of Cdrlp from the membrane to inside the cells becomes noticeable; strong fluorescence can be observed there in the stationary phase of growth (Figures 1B,C), although we do not see drop in pumps activity.

\section{Glucose Causes de Novo Synthesis of Cdr1p in CDR2 $\Delta$}

The most important factor in the activity of $\mathrm{ABC}$ transporters is ATP energy. C. albicans is a Crabtree-negative yeast and retains respiratory activity during growth at high glucose concentrations. Cdr1p and Cdr2p are up-regulated in the presence of glucose and this process probably increases resistance to azoles (Rodaki et al., 2009). To see if diS- $C_{3}(3)$ export can be facilitated by glucose 
we added it at the beginning of the experiment. In the early log-phase of growth (Figure 1A) glucose promotes dye efflux but this effect fades in further stages of culture (14 h late-log and 24 h stationary phase; Figures $\mathbf{1 B}, \mathbf{C})$. Interestingly the most marked change could be observed in $c d r 2 \Delta$ strain (Figure 2B). In the experiment without glucose $C D R 1$ pump was inactive (Figure 2B) and the difference in $\lambda_{\max }$ between it and after the addition of glucose was more pronounced than in the strain with both pumps (Figures 2A,B). This fact indicates that Cdr2p actively participates in removing $\operatorname{diS}-\mathrm{C}_{3}(3)$ from the fungal cells.

We used standard molecular methods to assess if the increased activity of Cdr1 under the influence of glucose was due to pump activation or pump overexpression. As shown in Figure 2D, western blot showed high levels of Cdr1 protein after induction of glucose in a strain lacking Cdr2p, whereas Cdr1p was observed at very low levels in control conditions (Figure 2D). In contrast, in the wild-type strain, Cdrlp was detected after $72 \mathrm{~min}$ but the level of this protein appeared to be the same, regardless of whether glucose was added (Figure 2D); this was reflected in both strains' diS- $\mathrm{C}_{3}(3)$ efflux. As shown in Figure 2C, $c d r 2 \Delta$ expresses $C D R 1$ continuously at a very low level. Glucose addition in $c d r 2 \Delta$ causes a twofold increase in CDR 1 expression after $12 \mathrm{~min}$ and fourfold increase after $36 \mathrm{~min}$. Interestingly, under the same conditions in the wild-type strain, CDR1 transcript level change is not detectable at $12 \mathrm{~min}$ after addition of glucose; after 36 min we observe a fivefold increase in transcript which do not correlate with protein level at this time point. This delayed response of wild-type strain to glucose may be a natural lag in between the gene expression and protein levels. Although $c d r 2 \Delta$ faster reaction could be a result of this strain need to complement deleted CDR2. Both gene expression and Western blotting suggested that glucose caused de novo synthesis of the Cdr1 pump in C. albicans $c d r 2 \Delta$.

$\mathrm{ABC}$ transporter upregulation in C. albicans can be caused by antifungal drugs (Henry et al., 1999; Coste et al., 2004; Schneider and Morschhäuser, 2015), antibiotics (Vogel et al., 2008), or human steroid hormones (Larsen et al., 2006; Banerjee et al., 2007). C. albicans is a human pathogen; environmental glucose may be another sign that yeast cells have entered the bloodstream and to adapt express a virulence phenotype. One of the virulence factors of C. albicans, its ability to form hyphal forms, can be

\section{REFERENCES}

Banerjee, D., Martin, N., Nandi, S., Shukla, S., Dominguez, A., Mukhopadhyay, G., et al. (2007). A genome-wide steroid response study of the major human fungal pathogen Candida albicans. Mycopathologia 164, 1-17. doi: 10.1007/s11046007-9025-8.

Brown, A. J. P., Brown, G. D., Netea, M. G., and Gow, N. A. R. (2014). Metabolism impacts upon Candida immunogenicity and pathogenicity at multiple levels. Trends Microbiol. 22, 614-622. doi: 10.1016/j.tim.2014.07.001

Cannon, R. D., Lamping, E., Holmes, A. R., Niimi, K., Baret, P. V., Keniya, M. V., et al. (2009). Efflux-mediated antifungal drug resistance. Clin. Microbiol. Rev. 22, 291-321. doi: 10.1128/CMR.00051-58

Coste, A. T., Karababa, M., Bille, J., and Sanglard, D. (2004). TAC1, transcriptional activator of CDR genes, is a new transcription factor involved in the regulation of Candida albicans ABC Transporters CDR1 and CDR2 †. Eukaryot Cell 3, 1639-1652. doi: 10.1128/EC.3.6.1639 triggered by addition of serum to cultures at $37^{\circ} \mathrm{C}$ (Hudson et al., 2004). The active component starting this process is glucose; changes in C. albicans transcriptome, including CDR1 and CDR2 (Rodaki et al., 2009), start as early as $30 \mathrm{~min}$ after the addition of no more than $0.01 \%$ glucose - a concentration much lower than that in human serum $(0.06-0.1 \%)$. Our results using diS$\mathrm{C}_{3}(3)$ also suggest that activation of Cdr1p under the influence of glucose results in overexpression of this pump, especially in case where CDR2 is deleted.

\section{CONCLUSION}

In this study, we showed that the diS- $\mathrm{C}_{3}(3)$ carbocyanine probe can be used as a multipurpose fluorescent assay.

- $\mathrm{DiS}_{-} \mathrm{C}_{3}(3)$ can be used to assess both membrane polarization and $\mathrm{ABC}$ transporter activity in C. albicans.

- Increase of the export diS- $\mathrm{C}_{3}(3)$ by glucose depends on growth phase and is the strongest at the beginning of the log-phase.

- In case of $c d r 2 \Delta$ strain observed increase in diS- $\mathrm{C}_{3}(3)$ export is caused de novo synthesis of Cdr1p.

\section{AUTHOR CONTRIBUTIONS}

JS execution of experiments; ML conceptual work; AK conceptual work and and writing publication.

\section{FUNDING}

This work was supported by Wroclaw Centre of Biotechnology, programme: The Leading National Research Centre (KNOW) for years 2014-2018.

\section{ACKNOWLEDGMENTS}

We thank Prof. Dominique Sanglard for kindly providing C. albicans strains and antibodies and Prof. Cheryl Gale and Fungal Genetics Stock Center for GFP plasmid.

Ene, I. V., Adya, A. K., Wehmeier, S., Brand, A. C., Maccallum, D. M., Gow, N. A. R., et al. (2012). Host carbon sources modulate cell wall architecture, drug resistance and virulence in a fungal pathogen. Cell. Microbiol. 14, 1319-1335. doi: 10.1111/j.1462-5822.2012.01813.x

Fonzi, W., and Irwin, M. (1993). Isogenic strain construction and gene mapping in Candida albicans. Genetics 134, 717-728.

Garreau, H., Hasan, R. N., Renault, G., Estruch, F., Boy-Marcotte, E., and Jacquet, M. (2000). Hyperphosphorylation of Msn2p and Msn4p in response to heat shock and the diauxic shift is inhibited by cAMP in Saccharomyces cerevisiae. Microbiology 146, 2113-2120. doi: 10.1099/00221287-146-9-2113

Gasch, A. P., Spellman, P. T., Kao, C. M., Carmel-Harel, O., Eisen, M. B., Storz, G., et al. (2000). Genomic expression programs in the response of yeast cells to environmental changes. Mol. Biol. Cell 11, 4241-4257. doi: 10.1091/mbc.11.12.4241

Gásková, D., Brodská, B., Herman, P., Vecer, J., Malínský, J., Sigler, K., et al. (1998). Fluorescent probing of membrane potential in walled cells: diS-C3(3) 
assay in Saccharomyces cerevisiae. Yeast 14, 1189-97. doi: 10.1002/(SICI)10970061(19980930)14:13<1189::AID-YEA320>3.0.CO;2-K

Gerami-Nejad, M., Berman, J., and Gale, C. A. (2001). Cassettes for PCR-mediated construction of green, yellow, and cyan fluorescent protein fusions in Candida albicans. Yeast 18, 859-864. doi: 10.1002/yea.738

Grossmann, G., Opekarová, M., Malinsky, J., Weig-Meckl, I., and Tanner, W. (2007). Membrane potential governs lateral segregation of plasma membrane proteins and lipids in yeast. EMBO J. 26, 1-8. doi: 10.1038/sj.emboj.7601466

Henry, K. W., Cruz, M. C., Katiyar, S. K., and Edlind, T. D. (1999). Antagonism of azole activity against Candida albicans following induction of multidrug resistance genes by selected antimicrobial agents. Antimicrob. Agents Chemother. 43, 1968-1974.

Hiller, D., Sanglard, D., and Morschhäuser, J. (2006). Overexpression of the MDR1 gene is sufficient to confer increased resistance to toxic compounds in Candida albicans. Antimicrob. Agents Chemother. 50, 1365-1371. doi: 10.1128/AAC.50.4.1365-1371.2006

Hudson, D. A., Sciascia, Q. L., Sanders, R. J., Norris, G. E., Edwards, P. J. B., Sullivan, P. A., et al. (2004). Identification of the dialysable serum inducer of germ-tube formation in Candida albicans. Microbiology 150, 3041-3049. doi: 10.1099/mic.0.27121-27120

Koh, A. Y. (2013). Gastrointestinal colonization of fungi. Curr. Fungal Infect. Rep. 7, 144-151. doi: 10.1007/s12281-013-0133-2

Kumar, A., Radhakrishnan, V. S., Singh, R., Kumar, M., Mishra, N. N., and Prasad, T. (2015). “A clinical resistant isolate of opportunistic fungal pathogen, Candida albicans revealed more rigid membrane than its isogenic sensitive isolate," in Multidisciplinary Approaches for Studying and Combating Microbial Pathogens, ed. A. Méndez-Vilas (Boca Raton, FL: BrownWalker Press), 1-7.

Larsen, B., Anderson, S., Brockman, A., Essmann, M., and Schmidt, M. (2006). Key physiological differences in Candida albicans CDR1 induction by steroid hormones and antifungal drugs. Yeast 23, 795-802.

Mandal, S. M., Mahata, D., Migliolo, L., Parekh, A., Addy, P. S., Mandal, M., et al. (2014). Glucose directly promotes antifungal resistance in the fungal pathogen Candida spp. J. Biol. Chem. 289, 25468-25473. doi: 10.1074/jbc.C114.5 71778

Mukhopadhyay, K., Prasad, T., Saini, P., Pucadyil, J., Chattopadhyay, A., Prasad, R., et al. (2004). Membrane sphingolipid-ergosterol interactions are important determinants of multidrug resistance in Candida albicans membrane sphingolipid-ergosterol interactions are important determinants of multidrug resistance in Candida albicans. Antimicrob. Agents Chemother. 48, 1778-1787. doi: 10.1128/AAC.48.5.1778

Murzyn, A., Krasowska, A., Stefanowicz, P., Dziadkowiec, D., and Łukaszewicz, M (2010). Capric acid secreted by S. boulardii inhibits C. albicans filamentous growth, adhesion and biofilm formation. PLoS ONE 5:e12050. doi: 10.1371/journal.pone.0012050

Pasrija, R., Panwar, S. L., and Prasad, R. (2008). Multidrug transporters CaCdrlp and CaMdrlp of Candida albicans display different lipid specificities: both ergosterol and sphingolipids are essential for targeting of CaCdr1p to membrane rafts. Antimicrob. Agents Chemother. 52, 694-704. doi: 10.1128/AAC.00861-867
Perlroth, J., Choi, B., and Spellberg, B. (2007). Nosocomial fungal infections: epidemiology, diagnosis, and treatment. Med. Mycol. 45, 321-346. doi: $10.1080 / 13693780701218689$

Plášek, J., and Gášková, D. (2013). Complementary methods of processing diSC3(3) fluorescence spectra used for monitoring the plasma membrane potential of yeast: their pros and cons. J. Fluoresc. 24, 1-7. doi: 10.1007/s10895-013-1323-

Plášek, J., Gášková, D., Lichtenberg-Fraté, H., Ludwig, J., and Höfer, M. (2012). Monitoring of real changes of plasma membrane potential by diS-C3(3) fluorescence in yeast cell suspensions. J. Bioenerg. Biomembr. 44, 559-569. doi: 10.1007/s10863-012-9458-8

Ricardo, E., Costa-de-Oliveira, S., Dias, A. S., Guerra, J., Rodrigues, A. G., and PinaVaz, C. (2009). Ibuprofen reverts antifungal resistance on Candida albicans showing overexpression of CDR genes. FEMS Yeast Res. 9, 618-625. doi: 10.1111/j.1567-1364.2009.00504.x

Rodaki, A., Bohovych, I. M., Enjalbert, B., Young, T., Odds, F. C., Gow, N. A. R., et al. (2009). Glucose promotes stress resistance in the fungal pathogen Candida albicans. Mol. Biol. Cell 20, 4845-4855. doi: 10.1091/mbc.E09-01-0002

Sanglard, D., and Ischer, F. (1996). Susceptibilities of Candida albicans multidrug transporter mutants to various antifungal agents and other metabolic inhibitors. Antimicrob. Agents Chemother. 40, 2300-2305.

Sanglard, D., Ischer, F., Monod, M., and Bille, J. (1997). Cloning of Candida albicans genes conferring resistance to azole antifungal agents: characterization of CDR2, a new multidrug ABC transporter gene. Microbiology 143, 405-416. doi: 10.1099/00221287-143-2-405

Schneider, S., and Morschhäuser, J. (2015). Induction of Candida albicans drug resistance genes by hybrid zinc cluster transcription factors. Antimicrob. Agents Chemother. 59, 558-569. doi: 10.1128/AAC.04448-4414

Szczepaniak, J., Łukaszewicz, M., and Krasowska, A. (2015). Detection of inhibitors of Candida albicans Cdr transporters using a diS-C3(3) fluorescence. Front. Microbiol. 6:176. doi: 10.3389/fmicb.2015.00176

Thomas, E., Roman, E., Claypool, S., Manzoor, N., Pla, J., and Panwar, S. L. (2013). Mitochondria influence CDR1 efflux pump activity, Hog1-mediated oxidative stress pathway, iron homeostasis, and ergosterol levels in Candida albicans. Antimicrob. Agents Chemother. 57, 5580-5599. doi: 10.1128/AAC.00889-813

Vogel, M., Hartmann, T., Köberle, M., Treiber, M., Autenrieth, I. B., and Schumacher, U. K. (2008). Rifampicin induces MDR1 expression in Candida albicans. J. Antimicrob. Chemother. 61, 541-7. doi: 10.1093/jac/dkm513

Conflict of Interest Statement: The authors declare that the research was conducted in the absence of any commercial or financial relationships that could be construed as a potential conflict of interest.

Copyright (C) 2015 Szczepaniak, Łukaszewicz and Krasowska. This is an open-access article distributed under the terms of the Creative Commons Attribution License (CC BY). The use, distribution or reproduction in other forums is permitted, provided the original author(s) or licensor are credited and that the original publication in this journal is cited, in accordance with accepted academic practice. No use, distribution or reproduction is permitted which does not comply with these terms. 